TELISIK

\title{
SEJARAH FAKULTAS SASTRA DAN KEBUDAJAAN UGM
}

\section{$1946-1982$}

\section{Musliichah ${ }^{l}$}

Perkembangan fakultas di lingkungan UGM sangat dinamis. Hal ini ditunjukkan dengan pendirian, pembubaran, penggabungan, pemekaran/pemecahan, maupun pergantian nama fakultas. Salah satu bukti dinamika tersebut adalah keberadaan Fakultas Sastra dan Kebudajaan UGM yang saat ini menjadi Fakultas Ilmu Budaya UGM. Nama Fakultas Sastra dan Kebudajaan UGM berlaku sejak tahun 1955 (sebelum tahun 1955 bernama Fakultas Sastra, Pedagogik dan Filsafat UGM) dan berakhir tahun 1982 (kemudian bernama Fakultas Sastra UGM). Fakultas Sastra UGM kemudian berganti nama menjadi Fakultas Ilmu Budaya UGM. Tulisan ini menyajikan informasi tentang perkembangan Fakultas Sastra dan Kebudajaan UGM dimulai dari embrio pendiriannya tahun 1946 hingga tahun 1982, ketika berganti nama menjadi Fakultas Sastra UGM. Informasi-informasi ini ditulis berdasarkan sumber arsip yang tersimpan di Arsip UGM sehingga penyebutan nama-nama lembaga atau unit-unit kerja masih menggunakan ejaan lama sesuai dengan kutipan pada sumber arsip.

\section{A. Sejarah Pendirian Fakultas Sastra dan Kebudajaan UGM}

Berdasarkan Peraturan Pemerintah No. 30 Tahun 1950 yang ditetapkan di Jogjakarta tanggal 14 Agustus 1950 tentang Mengubah Bentuk dan Susunan Universitas Gadjah Mada pasal 4 disebutkan bahwa telah resmi didirikan Fakultit Sastra, Pedagogik, dan Filsafat pada tanggal 23 Januari 1951. Sebagai Ketua Fakultit Sastra, Pedagogik, dan Filsafat saat itu adalah Prof. Drs. A. Sigit.

\section{Arsiparis Arsip UGM}




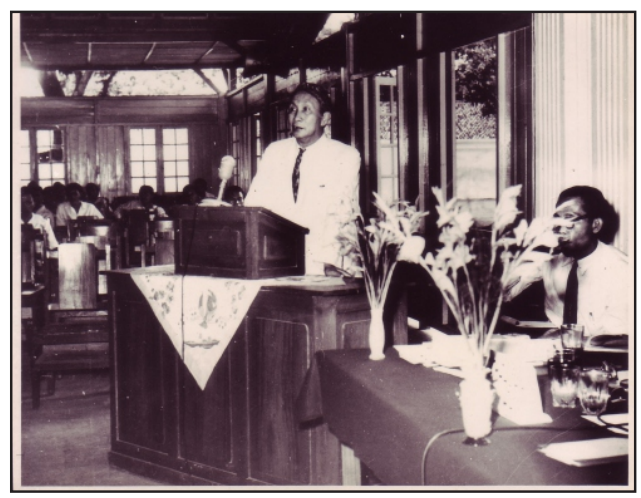

Prof. Drs. A. Sigit, saat menjadi pemrasaran dalam Seminar Kembali ke UUD 1945 dan Follow up-nya di Sitihinggil 26 April 1959 (Sumber: AF2/AM.MS/1959-1K)

Fakultit Sastra, Pedagogik, dan Filsafat merupakan penjelmaan dari Fakultit Sastra dari Universitit Gadjah Mada yang telah berdiri sejak permulaan revolusi di Jogjakarta. Fakultas ini didirikan pada tanggal 3 Maret 1946. Ketika didirikan, fakultas ini bernama Faculteit Sastra, Filsafat, dan Keboedajaan.

Ketua Jajasan Fakultit Sastra adalah Prof. Dr. R. Prijono yang kemudian digantikan oleh Prof. Dr. M. Ng. Poerbatjaraka. Tenaga pengajar/dosen pada masa itu adalah sebagai berikut:

1. R.J. Katamsi, yang kemudian menjadi dosen tidak tetap di Fakultas Sastra dan Kebudajaan UGM
2. Ki R. D. D. Hadiwijono, yang kemudian menjadi dosen tidak tetap di Fakultas Sastra dan Kebudajaan UGM

3. Ir. Marsito, yang kemudian menjadi dosen tidak tetap di Fakultas Sastra dan Kebudajaan UGM

4. R. Soemadi Soemowidagdo, yang kemudian menjadi dosen tetap Fakultas Sastra dan Kebudajaan UGM

5. Siti Baroroh Baried, yang kemudian menjadi dosen tetap Fakultas Sastra dan Kebudajaan UGM

6. Tudjimah, yang kemudian menjadi dosen di Universitas Indonesia

7. R.M. Kuntjaraningrat

8. R. B. Slamet Muljono

9. R.M. Soetjipto Wirjosoeparto

Tahun 1955 terbit Putusan Menteri PP \& K No. 53579/Kab tanggal 15 September 1955 tentang Melengkapkan Susunan UGM. Pada pasal 5 dijelaskan:

1. Bagian Sastra dan Filsafat dari Fakultas Sastra, Pedagogik dan Filsafat diubah menjadi: 
a. Fakultas Sastra dan Kebudajaan yang terdiri atas Bagian Sastra dengan mempunyai Jurusan Sejarah dan Jurusan Ilmu Bumi Alam dan Ilmu Bumi Sosial dan Bagian Kebudajaan

b.Fakultas Filsafat yang mempunyai tingkat pelajaran Baccalaureat Ilmu Filsafat

2. Bagian Pedagogik dari Fakultas Sastra, Pedagogik dan Filsafat diubah menjadi Fakultas Ilmu Pendidikan yang terdiri atas Bagian Pendidikan dan Bagian Pendidikan Djasmani

3. Untuk kepentingan koordinasi Fakultas Sastra dan Kebudajaan dan Fakultas Ilmu Pendidikan buat sementara waktu dipersatukan dalam suatu persatuan fakultas disebut Persatuan Fakultas Sastra dan Kebudajaan dan Fakultas Ilmu Pendidikan.

Sejak tahun ajaran 1955/1956 dengan terbitnya Putusan Menteri PP \& K No. 53579/Kab tanggal 15 September 1955 menandai resminya nama Fakultas Sastra dan Kebudajaan UGM.

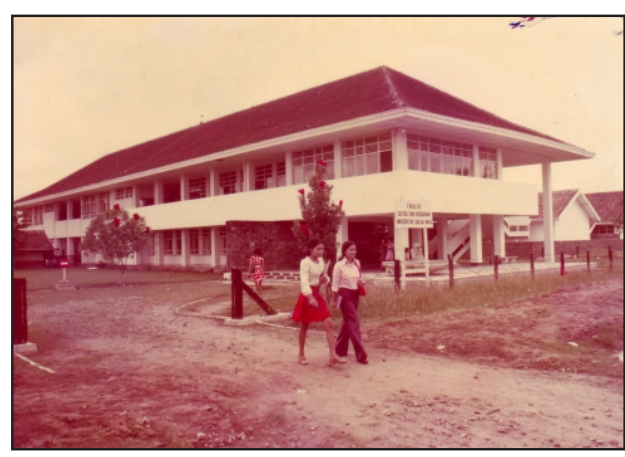

Foto Suasana dan Gedung Fakultas Sastra dan Kebudayaan UGM Tahun 1974

(Sumber: AF1/IP.IG/1974-19A)

\section{B. Perkembangan dan Perubahan}

Da 1 a m perjal a n a n sejarahnya, fakultas ini mengalami enam kali perubahan nama, yaitu Faculteit Sastra dan Filsafat (19 Desember 1949 - 13 Agustus 1950), Faculteit Sastra, Pedagogik, dan Filsafat (14 Agustus 1950 - 14 Oktober 1955), Fakultas Sastra dan Kebudajaan(15 Oktober 1955 - 6 Oktober 1982), Fakultas Sastra (7 Oktober 1982 - 22 Juni 2001), dan Fakultas Ilmu Budaya (23 Juni 2001 - sekarang). Perubahan nama dari Faculteit Sastra, Filsafat, dan Keboedajaan menjadi Faculteit Sastra dan Filsafat itu bertepatan dengan berdirinya Universitas Gadjah 
Mada pada tanggal 19 Desember 1949 sebagai Universitas Negeri pertama di Indonesia. (Sumber: http://www.fib.ugm.ac.id)

Tahun 1963, terjadi pemekaran Fakultas Sastra dan Kebudayaan menjadi dua fakultas yaitu Fakultas Sastra dan Kebudayaan dan Fakultas Geografi. Terbitnya Keputusan Menteri Perguruan Tinggi dan Ilmu Pengetahuan No. 109 Tahun 1963 menjadi dasar pemisahan Jurusan Ilmu Bumi Alam dan Ilmu Bumi Sosial dari Bagian Sastra Fakultas Sastra dan Kebudajaan UGM menjadi Fakultas Geografi. (Sumber: AS1/SC.PM/3.4).

Perjalanan sejarah menunjukkan bahwa beberapa fakultas yang ada di Universitas Gadjah Mada saat ini, seperti Bagian Ilmu Bumi yang menjadi Fakultas Geografi, Bagian Filsafat yang menjadi Fakultas Filsafat, dan Bagian Pedagogik yang menjadi Fakultas Psikologi, semula merupakan bagian dari Fakultas Ilmu Budaya. Bahkan, Fakultas Ilmu Budaya merupakan cikal bakal lembaga pendidikan yang kemudian berkembang menjadi IKIP Yogyakarta atau sekarang Universitas Negeri Yogyakarta. (Sumber: http://ugm.ac.id/id/ akademik/1451-fakultas.ilmu. budaya)

\section{Penyelenggaraan Pendidikan}

Fakutas Sastra dan Kebudajaan UGM bertujuan mendidik dan mempersiapkan tenaga-tenaga ahli dalam ilmu sastra dan kebudayaan, sedang bagian Pendidikan Guru menyelenggarakan pendidikan tenaga-tenaga pengajar sekolah lanjutan atas dalam mata pelajaran sastra dan kebudayaan. Ketua Fakultas Sastra dan Kebudajaan UGM pada saat berdiri adalah Prof. Dr. R.M. Ng. Poerbatjaraka. Sekretaris Ketua Fakultas Sastra dan Kebudajaan UGM adalah R. Soemadi $\mathrm{S}$ o e $\mathrm{m}$ o w i d a $\mathrm{g} \mathrm{d}$ o. Penyelenggaraan pendidikan dibantu oleh ketua-ketua jurusan. Pada tanggal 15 Juni 1961 dikeluarkan "Penetapan UGM 
sebagai Universitas SosialisIndonesia" dan Rancangan Kerja Universitas untuk menunaikan darma baktinya bagi Pembangunan Nasional-Semesta Berentjana. Hal ini mendorong Fakultas Sastra dan Kebudajaan UGM untuk melakukan perubahan kurikulum.

Tahun 1961 Fakultas Sastra dan Kebudajaan UGM memiliki jurusan:

1. Djurusan Sastra Indonesia, dipimpin Dra. Nj. Siti Baroroh Baried

2. Djurusan Sastra Djawa, dipimpin oleh Dra. Nj. Siti Baroroh Baried

Kedua jurusan ini merupakan pecahan dari Djurusan Sastra Timur yang pada hakikatnya dan sesungguhnya memuat Djurusan Sastra Indonesia dan Sastra Djawa

3. Djurusan Sastra Inggris, dipimpin oleh Dra. Soeratning

4. Djurusan Sejarah, dipimpin oleh Drs. A. Sartono Kartodirdjo

5. Djurusan Ilmu Bumi, dipimpin oleh Prof. Ir. R. Harjono Danusastro

Fakultas ini mengajarkan berbagai bahasa daerah Indonesia seperti bahasa Madura dan bahasa Minangkabau. Bahasa dan kebudayaan negara lain juga diajarkan seperti bahasa dan kasusasteraan Tionghoa dan kebudayaan Tiongkok.

Perkuliahan Fakultas Sastra dan K e b u d a j a a n U G M diselenggarakan di 4 lokasi yaitu:

1. Pusat, Sastra Indonesia, dan Djawa di Jalan Judonegaran Nomor 37 Jogjakarta

2. Sastra Inggris di Jalan $P$. Senopati Nomor 2 Jogjakarta dan Jalan Judonegaran nomor 37 Jogjakarta

3. Sedjarah di Jala n Judonegaran Nomor 5/38 Jogjakarta

4. Ilmu Bumi di Dalem Tjondrokiranan P.B.I/11 Jogjakarta

\section{Fasilitas Perpustakaan}

Berdasarkan Pedoman Fakultas Sastra dan Kebudayaan UGM TA 
1961/1962, perpustakaan terdiri dari:

1. Perpustakaan Pusat UGM berlokasi di Gedung Unit V Sekip

2. Perpustakaan Fakultas Sastra dan Kebudajaan UGM di Jalan Judonegaran nomor 37

3. Perpustakaan jurusan yang terdiri dari:

a. Perpustakaan Djurusan Sastra Indonesia/Djawa di Fakultas Sastra dan Kebudajaan UGM dan di Perpustakaan Prof. Dr. P. J. Zoetmulder di Gereja Kemetiran

b. Perpustakaan Djurusan Sastra Inggris di Fakultas Sastra dan Kebudajaan UGM

c. Perpustakaan Djurusan Sejarah di Fakultas Sastra dan Kebudajaan UGM

d. Perpustakaan Djurusan Ilmu Bumi di Dalem Tjondrokiranan

Buku-buku koleksi perpustakaan diperoleh dari pembelian, pertukaran, dan hibah/bantuan dari negara-negara asing, yayasan, badan-badan, dan perseorangan. Beberapa Negara dan badan yang memberikan bantuan buku adalah British Council, USIS, $I C A$, Keduataan Besar Rusia,
Colompo Plan, dan negara-negara Eropa.

\section{Peraturan Perkuliahan}

Dalam Pedoman Fakultas Sastra dan Kebudayaan UGM TA 1961/1962 dijelaskan bahwa tahun pengajaran Fakultas Sastra dan Kebudajaan mulai tanggal 1 September dan berakhir pada tanggal 31 Agustus. Dalam tiap tahun ajaran ada libur kuliah sebagai berikut:

1. Liburan bulan puasa selama enam minggu yang mulai pada hari kerja terakhir sebelum tanggal 1 puasa;

2. Satu atau dua liburan kwartalan, masing-masing satu sampai dua minggu menurut ketetapan Presiden Universitas

3. Liburan semester selama dua sampai tiga minggu menurut ketetapan Presiden Universitas

4. Liburan akhir tahun pengajaran selama enam minggu yang berakhir pada hari sebelum permulaan tahun pengajaran

5. Pada hari-hari raya resmi tidak diadakan perkuliahan

Selain hari libur, ada hari-hari penting tingkat universitas yaitu :

1. Tiap tanggal 19 September 
diadakan rapat Senat Terbuka UGM

2. Tiap tanggal 19 Desember diadakan peringatan Dies Natalis UGM

Seluruh Mahasiswa Fakultas Sastra dan Kebudajaan UGM wajib mengikuti mata kuliah stadium generale yang diberikan mulai tingkat pertama sampai tingkat terakhir dan merupakan mata kuliah wajib. Pelaksanaan stadium generale dilaksanakan oleh Fakultas Filsafat dan Umum. Mata kuliah ini baru diujikan sebagai testimonium pada tingkat doktoral.

\section{Tenaga Pengajar}

Sesuai dengan Pedoman Fakultas Sastra dan Kebudayaan UGM TA 1961/1962, tenaga pengajar Fakultas Sastra dan Kebudajaan UGM terdiri dari:

1. Guru Besar: Prof. Dr. R. M. Ng. Purbatjaraka dan Prof. Dr. P. J. Zoetmulder

2. Buru Besar Luar Biasa: Prof. Mr. M.M. Djojodiguno; Prof. Ir. R. Harjono Danusastro; Prof. Iso Reksohadiprodjo; Prof. Dr. R. M. Kuntjaraningrat; Prof. Drs. Mr.
Notonagoro; Prof. Mr. Notosusanto; dan Prof. Dr. R.B. Slamet Muljono

3. Guru Besar Ikatan Dinas Pendek: Prof. Dr. M. Halim Khan

4. Dosen Ikatan Dinas Pendek: R.S. Hornsey, B.A.; Prof. K.H. Lendon, B.A. Ph.D.; S.B. Mookherjee, MA.; dan R.A. Owen, B.A.

5. Lektor Kepala: R. Soemadi Soemowidagdo dan R. Soeroso Notohadiprawiro.

6. Lektor: Drs.A.Sartono Kartodirdjo dan Dra. Nj. Siti Baroroh Baried.

7. Lektor Muda

8. Dosen Luar Biasa

9. Asisten Ahli Luar Biasa

10. Asisten Kepala

11. Asisten

12. Asisten Luar Biasa

13. Mahasiswa Pembantu

\section{Penelitian dan Penerbitan}

Sesuai dengan Pedoman Fakultas Sastra dan Kebudayaan UGM TA 1961/1962, Fakultas Sastra dan Kebudajaan UGM memiliki unit-unit penelitian dan penerbitan yang meliputi:

1. Bidang Bahasa, Sastra, dan Budaya Bidang ini melaksanakan usaha dan 
kegiatan yang meliputi:

a. mengadakan ceramah-ceramah

b. mengadakan perlengkapan studi seperti pengadaan buku, pembuatan diktat, terjemahan, dll.

c. mengadakan penelitian ilmiah bidang bahasa, sastra, dan budaya

d. mengusahakan publikasi hasilhasil penelitian

Pengurus bidang ini terdiri dari:

Koordinator: Drs. Moch. Ramelan

Sekretaris : Dra. Siti Ismusilah Purbaningrat

Untuk melaksanakan usaha dan kegiatan-kegiatan tersebut, Bidang Bahasa, Sastra dan Budaya terdiri dari:

a. Bahasa dan Sastra

1) Seksi Kesusasteraan Indonesia

Pimpinan : Dra. Siti Sundari Tjitrosubono

Anggota : Ramly Leman dan J. Soekardjo

2) Seksi Bahasa Indonesia Pimpinan: Drs. Moch. Ramelan Anggota : Sjukur Widyotanojo dan Anton Lake

3) Seksi Bahasa dan Kasusastraan Djawa
Pimpinan : Dra. Sri Soekesi Adiwimarto

A ng got a: S u d a r d jo Padmowisastro

4) Seksi Bahasa dan Kasusastraan Melaju

Pimpinan : Dra. Siti Baroroh Baried

Anggota : Narantaka, B.A.

5) Seksi bahasa dan Kasusastraan

Djawa Kuno

Pimpinan : Drs. Supomo Surjohudojo

6) Seksi Bahasan dan Kasusastraan Daerah

Pimpinan: Amin Soedoro

b. Budaya

1) Seksi Sejarah Lokal

Pimpinan : Drs. Benny Oetojo

Anggota : Soetedjo

2) Seksi Sejarah Kolonial

Pimpinan: Soehardjo

Harmosoeprobo,

B.A.

Anggota: Darsiti Soeratman, B.A. dan Darmono, B.A.

3) Seksi Sejarah Pergerakan dan Revolusi Nasional

Pimpinan : T. Ibrahim Alfian, M.A. 
Anggota : Taufil Abdullah, B.A. dan Arief Iskandar, B.A.

4) Seksi Sejarah Hubungan Indonesia dengan Negeri Luar Pimpinan : Soeri Soeroto, M.A.

Anggota : R.M. Soedarsono, B.A.

5) Seksi Archeologi

Pimpinan : Sudiman

Anggota : Djoko Soemitro, B.A. dan Ibnu Ruslan

6) Seksi Antropologi Budaya Pimpinan : Soetjipto, B.A. Anggota : Dra. Soemarti Soeprajitno

c. Penerbitan

Pimpinan : Ibrahim Alfian, M.A. Anggota : Djoko Soemitro, B.A. dan Ibnu Ruslan

Pada tahun 1969, Fakultas Sastra dan Kebudajaan U GM menerbitkan buletin dengan nama "Buletin Fakultas Sastra dan Kebudajaan"

2. Bidang Ilmu Bumi

Bidang Ilmu Bumi terdiri dari:

a. Seksi-seksi Penelitian:
1) Sosial Ekonomi, dipimpin oleh Prof. Dr. M. Halim Khan

2) Morfologi, dipimpin oleh Drs. Kardono Darmojuwono

3) Kartografi, dipimpin oleh Drs. Basuki Sudihardjo

b. Lembaga Research dipimpin oleh Prof. Dr. M. Halim Khan

c. Majalah

Redaksi/Pengurus Harian terdiri dari: Prof. Dr. M. Halim Khan, Drs. R. Bintarto, Basuki Sudihardjo, R. Soetanto, B.A., Emon Supardjan, B.A., Riendarti Soewito, B.A., dan Poetoet Agoeng, B.A. Majalah yang telah diterbitkan adalah "Majalah Ilmu Bumi Indonesia".

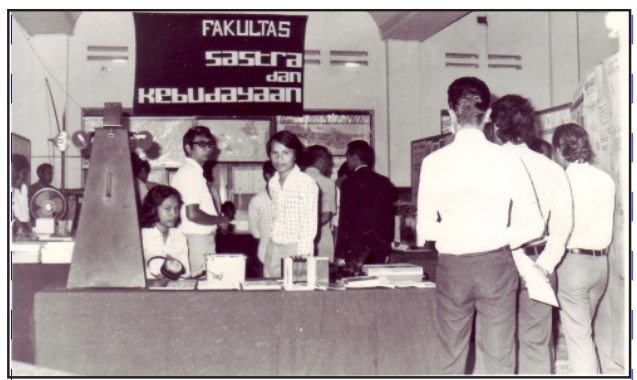

Foto salah satu kegiatan Fakultas Sastra dan Kebudayaan berupa pameran Tahun 1973

(Sumber: AF1/AA.AD/1973-13N)

\section{Organisasi Mahasiswa}

Organisasi Mahasiswa Fakultas Sastra dan Kebudajaan UGM berdasarkan Pedoman Fakultas Sastra 
dan Kebudayaan UGM TA 1961/1962 terdiri dari:

\section{Dewan Mahasiswa UGM}

2. Dewan Mahasiswa Komisariat Fakultas Sastra dan Kebudajaan

3. Sub Komisariat Jurusan-Jurusan

4. Badan Pengurus Angkatan:
a. Doktoral
b. Bakaloreat

Organisasi tersebut memiliki seksiseksi yang terdiri dari:

1. Seksi Pendidikan Mahasiswa

Seksi ini bertugas untuk mengusahakan diskusi-diskusi ilmiah, penerbitan diktat, dan penerbitan majalah.

2. Seksi Kesejahteraan

Seksi ini bertugas untuk mengusahakan kesejahteraan mahasiswa dan umum.

3. Seksi Kesenian

Seksi ini bertugas untuk menggerakkan bidang seni, membentuk klub drama, dan melakukan pentas seni.

4. Seksi Keolahragaan

Seksi ini bertugas untuk menggiatkan kegiatan olahraga dan melakukan pertandingan antar fakultas.

5. Seksi Keputrian
Seksi ini khusus bergerak di bidang keputrian.

6. Seksi Penerangan-Dokumentasi Seksi ini bertugas untuk memberikan penerangan tentang kemahasiswaan baik ke dalam maupun ke luar, menerbitkan brosur-brosur yang bersifat informatif, dan mengadakan dokumentasi peristiwa-peristiwa penting di lingkungan fakultas.

\section{Organisasi Informal}

Fakultas Sastra dan Kebudajaan UGM memiliki organisasi informal terdiri dari:

1. Ikatan Keluarga Fakultas Sastra dan Kebudajaan

Organisasi ini dibentuk untuk menjalin hubungan dan kekeluargaan antara dosen, asisten, dan pegawai. Susunan pengurus terdiri dari:

Ketua : Soeri Soeroto, M.A.

Penulis : Sabarijo

Bendahara : Drs. Soedarmo

Anggota : D r s . S u p o m o Surjohudojo, Drs. Djalinus Sjah, BA. dan Soewolo 
2. Badan Penasehat Keputrian

Organisasi ini dibentuk untuk memberikan pendampingan kepada mahasiswa putri Fakultas Sastra dan Kebudajaan UGM pada umumnya dan khusunya mereka yang berasal dari luar daerah Yogyakarta. Badan Penasehat Keputrian ini beranggotakan: Dra. Siti Baroroh Baried, Dra. Sri Soekesi Adiwimarto, Dra. Soeratning, Dra. Siti Sundari Tjitrosubono, Dra. Soelastin Soetrisno, Dra. Siti Ismusilah Purbadiningrat, Soekilah Bongsodjemiko, M.A. dan Moentiari Bakri, B.A.

\section{Sumber:}

1. Buku Pedoman Fakultas Sastra dan Kebudajaan UGM TA 1961/1962 (AS/RC.PF/7.2)

2. Keputusan Menteri Perguruan Tinggi dan Ilmu Pengetahuan No. 109 Tahun 1963 (AS1/SC.PM/3.4)

3. Buletin Fakultas Sastra dan
Kebudajaan Nomor 1 (AS4/PA.TF/2)

4. Surat Perjanjian Pemborongan Pembangunan Gedung Kuliah Fakultas Sastra dan Kebudayaan 2 1 a n t a $\mathrm{T}$ a h u n 1980 (AS6/IP.TG.01/7.1)

5. Surat Perjanjian Pemboronan Pembangunan Gedung Kuliah/ Lab. Fakultas Sastra dan Kebudayaan 3 lantai 1996 (AS6/IP.TG.01/7.5)

6. Foto Gedung Fakultas Sastra dan Kebudayan Tahun 1974 (AF1/IP.IG/1974-19A)

7. Foto Dekan Fakultas Sastra dan Kebudajaan sebagai Pemateri dalam Seminar Kembali ke UUD 1945 dan Follow up-nya 26 April 1959 (AF2/AM.MS/1959-1K)

8. Foto Stand pameran ilmiah Fakultas Sastra dan Kebudayaan (AF1/AA.AD/1973-13N). 